\section{DOIS PARADIGMAS DA PSICOSE NO ENSINO DE LACAN $^{1}$}

\author{
Two Paradigms of Psychosis in the Theory of Lacan \\ Dos Paradigmas de la Psicosis en Lacan \\ Deux Paradigmes de la Psychose dans L'enseignement de \\ Lacan
}

\begin{abstract}
Resumo
Neste artigo, trata-se de situar o conceito de psicose a partir de dois paradigmas: o paradigma Schreber, no Seminário 3 (1955-1956) e no texto De uma questão preliminar (1958) - no qual temos uma psicose francamente desencadeada; e o paradigma Joyce, no Seminário 23 (19751976) - no qual Lacan deduz uma estrutura psicótica, sem desencadeamento. Podemos dizer que há uma primeira clínica no começo do ensino de Lacan que se pauta nas estruturas: neurose, psicose e perversão. O primeiro Lacan formalizou o inconsciente baseado no conceito saussuriano do signo e elaborou os conceitos de Nome-do-Pai e metáfora paterna enunciando seu axioma fundamental: o inconsciente é estruturado como linguagem. A segunda fase do ensino de Lacan é considerada por Jacques-Alain Miller como uma fase de transição, pois ele subverte o Nome-do-Pai por uma pluralização e considera a operação de recalcamento não mais como atribuída à interdição paterna, mas à ação da linguagem. Lacan, na conclusão do Seminário 10 (1962-1963), destaca então o fim do Nome-do-Pai, substituindo-o por sua pluralização, os Nomes-do-Pai. A partir do paradigma Joyce, temos uma outra perspectiva da psicose, abordada sob o viés do sinthoma. A partir daí, podemos pensar em múltiplas soluções encontradas pelo sujeito para lidar com sua psicose. A teoria lacaniana dos nós nos permite abordar a singularidade das soluções inventadas pelos sujeitos através da amarração única que cada um faz dos três registros: o real, o simbólico e o imaginário.
\end{abstract}

Palavras-chave: psicose; schreber; Joyce; desencadeamento; suplência.

\section{Abstract}

This article is about the concept of psychosis through the view of two paradigms: The Schreber paradigm, in Seminar 3 (1955-1956) and the text On a question preliminary (1958) - In which we have a truly triggered psychosis; and the Joyce paradigm, of Seminar 23 (1975-1976) - in which Lacan deduces a psychotic structure without the triggering. Is possible to say that there is a first clinic in the beginning of Lacan's study, based on the structures: neurosis, psychosis and perversion. The first Lacan formalized the unconscious based on the saussurian concept of sign and elaborated the concepts Name-of-the-Father and Paternal Metaphor, announcing his fundamental axiom: the unconscious structured as language. The second stage of Lacan's study is considered by Jacques-Alain Miller as a transition stage, cause it subverts the Name-of-the-Father by its pluralization and considers that the repression operation can no more be attributed to the paternal interdiction, but to the action of the language. Lacan in his conclusion of Seminar 10 (1962-1963), highlights the end of the Name-of-the-Father, and substitutes by its pluralization, the Names-of-the-Father. From the Joyce paradigm, we have another perspective of psychosis, approached through the sinthome. From this start, is possible to think in multiple solutions founded by the subject to deal with his psychosis. The lacanian knots theory, allow us to approach the singularity of the invented solutions of the subjects through the unique lashing that each one does, of the three components of the reality: the real, the symbolic and the imaginary.

Keywords: psychosis; schrebe; Joyce; the knots theory; triggering; suppleance.

1 Este artigo é parte da dissertação de mestrado intitulada Do enlace entre toxicomania e psicose: Os usos do objeto droga defendida no Programa de Pós-Graduação em Psicologia da PUCMinas em 15 de Junho de 2012, sob orientação da Profa. Dra. Cristina Marcos.
Artigo Original

\section{Flávia Costa Tótoli ${ }^{(1)}$ \\ Cristina Moreira Marcos ${ }^{(2)}$}

1) Mestre em Psicologia pela Pontifícia Universidade Católica de Minas Gerais. Docente de Graduação e Pós-Graduação e Coordenadora da Pósgraduação Stricto Sensu "Saúde Mental : Da política à práxis" da Faculdade Santo Agostinho.

2) Doutoranda em Psicanálise pela Universidade de Paris 7. Docente do Programa de Pós-Graduação em Psicologia da PUC/Minas.
Recebido em: 09/07/2013

Revisado em: 05/12/2013

Aceito em: 09/12/2014 


\section{Resumen:}

Este artículo sitúa el concepto de psicosis a partir de dos paradigmas: el paradigma de Schreber, en el Seminario 3 (1955-1956) y el texto de una cuestión previa (1958) - en los que tenemos una psicosis activa, francamente, el paradigma Joyce, en el Seminario 23 (1975-1976) - en la que Lacan plantea una estructura psicótica sin activar. Podemos decir que hay una primera clínica en el inicio de la enseñanza de Lacan que se guía en las estructuras: neurosis, psicosis y perversión. El primer Lacan formalizó el inconsciente basado en el concepto del signo de Saussure y elaboró los conceptos del Nombre del Padre, y la metáfora paterna indicando su axioma fundamental: el inconsciente está estructurado como lenguaje. La segunda fase de la enseñanza de Lacan es considerado por Jacques-Alain Miller como una fase de transición, ya que subvierte el Nombre del Padre por una pluralización y considera que la operación de la represión ya no lo atribuye a prohibición paterna, pero la acción de la lengua. Lacan en la conclusión del Seminario 10 (1962-1963), entonces el final del Nombre del padre, sustituyéndolo por su pluralización, los Nombres del Padre. Desde el paradigma Joyce, abre otra perspectiva de la psicosis. A partir de ahí, podemos pensar en varias soluciones encontradas por objeto hacer frente a la psicosis. Una teoría lacaniana de nudos nos permite abordar la singularidad de las soluciones inventadas por el sujeto a través del amarre sólo lo que hace cada uno de los tres registros: lo real, lo simbólico y lo imaginario.

Palabras clave: psicosis; schreber; Joyce; desencadenamiento; suplencia.

\section{Résumé:}

Dans cet article, il s'agit de situer le concept de la psychose a partir de deux paradigmes: le paradigme Schreber, dans le Séminaire 3 (1955-1956) et dans le texte D’une question préliminaire (1958) dans lequel nous avons une psychose déclenché; et le paradigme Joyce, dans le Séminaire 23 (1975-1976) - dans lequel Lacan déduit une structure psychotique, sans déclenchement. Nous pouvons dire qu'il y a une première clinique dans l'enseigment de Lacan qui se fonde dans les structures: la névrose, la psychose et la perversion. Le premier Lacan a abordé l'inconscient a partir du concept saussurien du signe et a élaboré les concepts du Nom du Père et de la Métaphore Paternelle. Son axiome fondamental est: l'inconscient est structuré comme un language. Le deuxième période de l'enseignement de Lacan est considéré par Jacques-Alain Miller comme une phase de transition, dans la mesure où il subvertit le Nom du Père par sa pluralisation et considère le refoulement plutôt dî̀ à l'action du langage qu'à l'interdiction paternelle. Lacan, dans la conclusion du Séminaire 10 (1962-1963), souligne la fin du Nom du Père, le remplaçant par sa pluralisation, les Noms du Père. A partir du paradigme Joyce, nous avons une outre perspective de la psychose, abordée par le versant du sinthome. A partir de là, nous pouvons penser à des multiples issues rencontrées par le sujet pour y faire avec sa psychose. La théorie lacanienne des noeuds nos permet d'aborder la singularité des solutions inventées par les sujets a travers le nouage unique que chaqu'un fait des trois registres: le réel, le symbolique et l'imaginaire.
Mots-clés: psychose; schreber; Joyce; déclenchement; suppléance.

Neste artigo, trata-se de situar o conceito de psicose a partir de dois paradigmas: o paradigma Schreber, no Seminário 3 (Lacan, 1997) e no texto De uma questão preliminar (Lacan, 1998a) - no qual temos uma psicose francamente desencadeada; e o paradigma Joyce, no Seminário 23 (Lacan, 2005c) - no qual Lacan deduz uma estrutura psicótica, sem desencadeamento. A partir do paradigma Joyce, temos uma outra perspectiva da psicose, abordada sob o viés do sinthoma. A partir daí, podemos pensar em múltiplas soluções encontradas pelo sujeito para lidar com sua psicose. A teoria lacaniana dos nós nos permite abordar a singularidade das soluções inventadas pelos sujeitos através da amarração única que cada um faz dos três registros.

Podemos dizer que há uma primeira clínica no começo do ensino de Lacan que se pauta nas estruturas: neurose, psicose e perversão. O primeiro Lacan formalizou o inconsciente baseado no conceito saussuriano do signo e elaborou os conceitos de Nome-do-Pai e metáfora paterna enunciando seu axioma fundamental: o inconsciente é estruturado como linguagem. A segunda fase do ensino de Lacan é considerada por Jacques-Alain Miller (n.d.) como uma fase de transição, pois ele subverte o Nome-do-Pai por uma pluralização e considera a operação de recalcamento não mais como atribuída à interdição paterna, mas à ação da linguagem. Lacan (2005a) na conclusão do Seminário 10, destaca então o fim do Nome-do-Pai, substituindo-o por sua pluralização, os Nomes-do-Pai.

A reviravolta decisiva desse segundo momento é a subversão do conceito de desejo pelo conceito de gozo. "Agora, ao invés de ressaltar a falta, Lacan vai enfatizar o que preenche a falta" (Motta, 2003, p.5). Há por fim o que Miller (2002) chamou de último ensino, cuja elaboração cobre a década de setenta e na qual o que prevalece é o conceito de gozo. Nesse momento do ensino de Lacan, a própria linguagem torna-se aparelho de gozo e o significante é um operador de gozo. Antes o conceito de gozo opunha-se ao de prazer, nessa nova proposição a oposição se dissolve, o prazer se transforma em um regime de gozo.

Lacan pensa agora ao nível da pulsão. Diferentemente do desejo, a pulsão não está articulada a uma defesa. Ele a resumiu numa fórmula, num aforismo de "Televisão": "o sujeito é feliz", que J.-A. Miller nos explicou. Ao nível da pulsão, o sujeito está sempre feliz. (Motta, 2003, p.6) 


\section{O Paradigma Schreber}

No primeiro momento do ensino de Lacan, o psicótico é definido como aquele que se encontra foracluído do discurso, onde não há barras para o Outro, que é consistente. Lacan (1999) em seu Seminário 5: As formações do inconsciente, diferencia a Verwerfung (foraclusão) da Verdrängung (recalque). O recalque é aquilo que está no Outro como significante, já a foraclusão é a falta que se dá na cadeia de significantes, a falta do Nome-do-Pai, o que caracteriza a psicose.

No ensino de Lacan, podemos encontrar dois grandes paradigmas para abordar a clínica das psicoses: O presidente Schreber, no Seminário 3 (Lacan, 1997) e no texto De uma questão preliminar (Laca, 1998a) - o paradigma de uma psicose francamente desencadeada; e o escritor Joyce, no Seminário 23 (Lacan, 2005c) - onde Lacan deduz nele uma estrutura psicótica, sem desencadeamento. Utilizaremos da abordagem destes dois paradigmas de acordo com a diacronia apresentada por Dafunchio (2008) para o ensino lacaniano.

Iniciaremos pelo primeiro paradigma lacaniano da psicose, o paradigma Schreber. Dois anos depois do Seminário 3, no texto "De uma questão preliminar", contemporâneo ao Seminário 5, Lacan dá forma ao que seria sua doutrina a respeito da psicose. Concebe uma primazia do simbólico sobre o imaginário, através da qual vai se deter nos restos simbólicos da estrutura e como estes afetam o imaginário. Para isso, usa o texto de Freud sobre o caso Schreber e se dedica a matematizá-lo (Dafunchio, 2008). Para este intento, cria inicialmente o esquema R, que retrata como se constrói o campo da realidade em um sujeito neurótico.

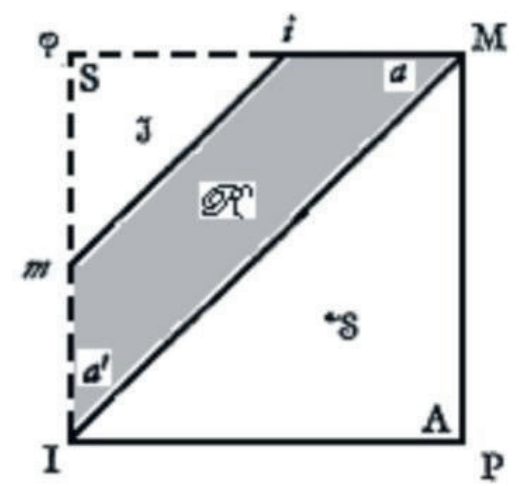

Figura 1. O esquema R (Lacan, 1998, p.559)

$\mathrm{O}$ esquema $\mathrm{R}$ consiste em dois grandes triângulos, o $\mathrm{S}$ e o I. O campo da realidade está inserido no triângulo I, na área que intercepta o registro $\mathrm{S}$. Esse esquema será o ponto de partida para estudar o que ocorre na estrutura psicótica, ilustrando no desencadeamento o declínio do campo da realidade, sobrevivendo a catástrofe imaginária. Lacan indica que as memórias de Schreber são o testemunho de um trabalho de reconstrução do campo da realidade que havia sido perdido no desencadeamento psicótico. Assim concebe o esquema I, onde tenta mostrar como se reconstrói o campo da realidade através do delírio.

Nesse esquema Lacan tem uma concepção deficitária da psicose, déficit esse simbólico. A psicose se desencadeia quando o sujeito requer o Nome-do-Pai no lugar do Outro. Este chamado não encontra resposta, tornando presente o furo no simbólico. Uma leitura possível do

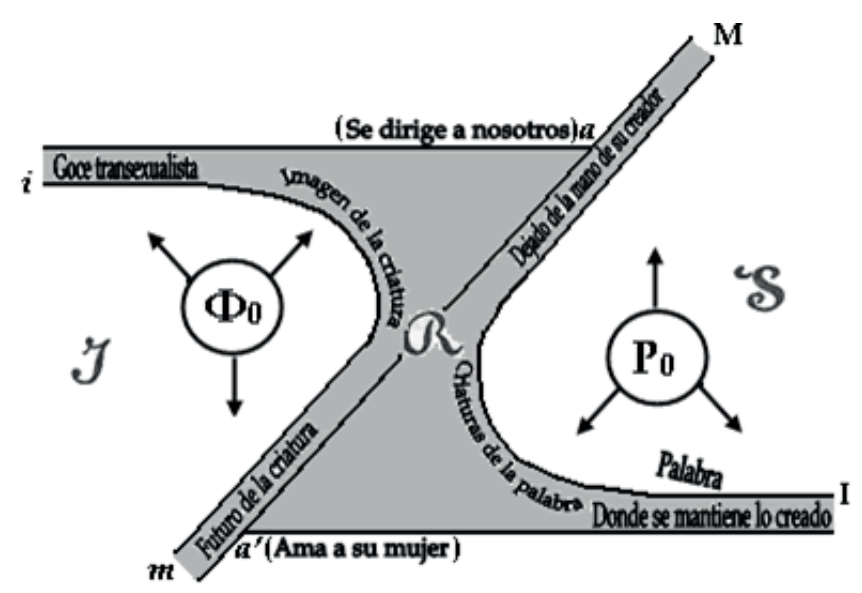

Figura 2. Esquema I (Lacan, 1998, p.578)

desencadeamento do Schreber, através do Seminário 3, seria sua nomeação como presidente da corte, que o leva a uma posição simbólica de pai. Já em De uma questão preliminar a leitura é feita a partir da presença de Fleshsig como Um-pai no real.

O encontro com este furo no simbólico, P0, vai abrir por sua vez um furo no imaginário. Desta maneira o triângulo imaginário se desarma ao ser habitado por um furo, aí se faz presente a foraclusão do falo. É então que o significante fálico se faz presente para o psicótico. (Dafunchio, 2008, p.25, [tradução nossa])

Lacan faz a apresentação do Esquema I de Schreber da seguinte maneira: Como lhe falta o Nome-do-Pai, Schreber o substitui alongando o vértice do Ideal (esquema R), fazendo-o vir no lugar no Nome-do-Pai. Assim o Ideal vai cumprir a função que não cumpre o Nome-do-Pai. Encontramos então o limite do paradigma de Schreber: sua estabilização se dá através do trabalho do delírio, da metáfora delirante. Esta solução não recobre totalmente o furo que o psicótico vivencia e o sujeito pode voltar a desencadear, como aconteceu ao Presidente. Segundo Dafunchio (2008), havia a ideia da direção da cura do psicótico se pautar por uma estabilização pela via de alguma metáfora delirante, 
mas na clínica encontramos vários casos onde os delírios não chegam a uma formulação metafórica, além da grande quantidade de psicóticos que não deliram. É este então, o limite do paradigma Schreber.

O segundo paradigma lacaniano sobre a psicose é o paradigma Joyce. Através das fórmulas de sexuação, Lacan faz a equivalência entre os três registros: real, simbólico e imaginário. A partir do último ensino o registro real sustenta uma existência própria e não é um produto da operação simbólica, como se teorizava no tempo anterior de seu ensino. Para explorarmos este paradigma, falaremos da psicose no chamado último ensino lacaniano.

Lacan introduz a função paterna como metáfora. A fórmula da metáfora ou da substituição significante é demonstrada por Lacan (1998a) em seu texto "De uma questão preliminar" da seguinte forma:

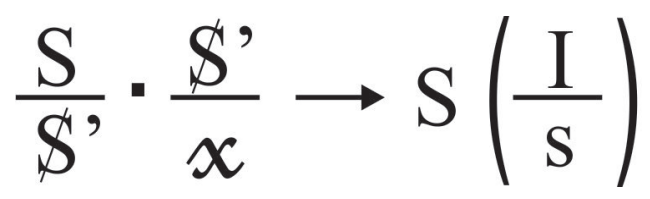

Figura 3. Fórmula da metáfora (Lacan, 1998, p. 563)

Nesta fórmula os $\mathrm{S}$ são significantes, $\mathrm{x}$ é a significação desconhecida e s é o significado induzido pela metáfora, que consiste na substituição, na cadeia significante, de $S^{\prime}$ por S. A elisão de S', representada por \$', é a condição de sucesso da metáfora.

Isso se aplica, assim, à metáfora do Nome-do-Pai, ou seja, à metáfora que coloca esse nome em substituição ao lugar primeiramente simbolizado pela operação da ausência da mãe (Lacan, 1998a, p. 563).

$\frac{\text { Nome-do-pai }}{\text { Desejo da mãe }} \frac{\text { Desejo da Mãe }}{\text { Significado para o sujeito }} \rightarrow$ Nome-do-pai $\left(\frac{\mathbf{A}}{\text { Falo }}\right)$

Figura 4. Fórmula da metáfora paterna

No Seminário 5, Lacan nos mostra que é no nível do Outro como tal que se situa a dialética do significante. Na estrutura promovida como sendo a da metáfora residem todas as possibilidades de articular claramente o complexo de Édipo e o que Lacan chama de seu móbil, o complexo de castração. Nesta estrutura, há a colocação substitutiva do pai como símbolo, ou significante, no lugar da mãe, no que foi constituído por uma simbolização primordial entre a criança e a mãe. O triângulo instituído filho-pai-mãe nos esclarece, então, sobre uma relação simbólica instituída no real. A primeira relação de realidade acontece entre mãe e filho.

Para desenhar objetivamente essa situação é feita a entrada do pai nesse triângulo, embora, para a criança, ele ainda não tenha entrado. O pai para nós é real, mas a posição do Nome-do-Pai se situa no nível simbólico, é uma necessidade da cadeia significante. Pelo simples fato da instituição da ordem simbólica pelo sujeito, alguma coisa corresponde ou não à função definida pelo Nome-do-Pai, e no interior dessa função, são colocadas significações que podem ser diferentes, conforme os casos, mas que de modo algum dependem de outra necessidade que não a necessidade da função paterna, à qual corresponde o Nome-do-Pai na cadeia significante. "É isso, portanto, que podemos chamar de triângulo simbólico, como instituído no real a partir do momento em que há uma cadeia significante, a articulação de uma fala" (Lacan, 1999, p. 187).

A partir deste momento, se faz necessário explicitar a relação da criança com a mãe, na medida em que a criança revela depender do desejo da mãe, da primeira simbolização da mãe como tal - ainda que a mãe já esteja submetida ao pai. Através dessa simbolização a criança desvincula sua dependência efetiva do desejo materno, da simples vivência dessa dependência e alguma coisa se institui, subjetivada. Essa subjetivação consiste em instaurar a mãe como um ser primordial que pode ou não estar presente. Por causa dessa primeira simbolização é que se esboçam todas as complicações, na medida em que o desejo da criança é o desejo do desejo da mãe, o que, segundo o autor, poderíamos chamar de desejo de Outra coisa. Essa simbolização se efetua de maneira falha, no sentido de que o sujeito precisa de um pouco mais do que essa simbolização primordial da mãe, que vai e vem, lhe dá, necessita de um "algo mais", de um objeto de desejo, do falo. Assim, Lacan estabelece uma relação de simetria, uma ligação metafórica entre o falo, que se encontra no vértice superior do ternário imaginário, e o pai, que se encontra no vértice inferior do ternário simbólico.

No primeiro momento do Édipo, a criança se encontra então, em um questionamento de ser ou não ser o falo. Nesse momento, a instância paterna se introduz de forma velada. Por causa disso, a questão do falo já está colocada em algum lugar da mãe, onde a criança tem de situá-la. Em um segundo momento, o pai intervém efetivamente como privador da mãe. O pai se afirma como aquele que é suporte de lei, e isso agora é feito de modo mediado pela mãe, que é quem o instaura como aquele que faz a lei. No terceiro momento, acontece o declínio do complexo de Édipo, é aí que o pai intervém como aquele que tem o falo, e a criança se identifica a ele. Essa identificação é o que Lacan chama de Ideal do eu. O menino renuncia a ser o falo materno e se engaja na dialética do ter, e a menina depara-se com a dialética do ter, sob a forma de não ter. Assim é colocada a importância do segundo momento do Édipo para o seu declínio, pois um desfecho favorável ou desfavorável 
gira em torno de três planos: a castração, a frustração e a privação, exercidas pelo pai.

O primeiro plano desse segundo momento é a castração. A castração é uma falta simbólica de um objeto imaginário. A ameaça de castração sofrida pelo sujeito é a intervenção real do pai no que concerne a uma ameaça imaginária. Ou seja, o pai real não castra no Real o filho. Ela é um ato simbólico, cujo agente é alguém real, e o objeto é imaginário, o menino se sente castrado por imaginá-la. Nesse plano, o pai efetivamente frustra o filho da posse da mãe.

Assim surge o segundo plano - o da frustração. O pai aí intervém como detentor de um direito, a mãe. Assim a ameaça é real e o agente é a mãe simbólica. Por que a mãe? Porque se o pai sustenta a lei, ela é mediada pela mãe, que é quem, como já foi dito, coloca o pai como aquele que lhe dita a lei. Por isso a frustração se caracteriza como a falta imaginária de um objeto real. $\mathrm{O}$ ato do pai é imaginário e frustra a criança da posse da mãe real.

Por fim, vem o terceiro plano, o da privação. Nesse plano o pai se faz preferir em lugar da mãe, ocupa o lugar anteriormente ocupado por ela. $\mathrm{Na}$ medida em que isso acontece é que se torna possível estabelecer a identificação final, aquela que leva à formação do Ideal do eu. Para o menino, a proibição do pai, e sua identificação como Ideal do eu, faz com que ele se identifique como aquele que tem o falo. Já na menina, o pai como Ideal do eu produz o reconhecimento de que ela não tem o falo. A saída do Édipo para o menino seria então não ter aquilo que realmente tem, o falo da mãe, que é o pai e para a menina não ter aquilo que realmente não tem. Por isso a privação se caracteriza pela falta real do objeto simbólico. O agente é o pai imaginário e a ameaça é simbólica. A privação é feita então pelo pai, que priva a mãe do que ela não tem, o falo.

No plano da privação da mãe, o sujeito tem então a opção de aceitar ou recusar, assumir ou não essa privação exercida pelo pai, ou seja, aceitar ou não o Nome-do-Pai. Esse ponto é o que Lacan chama de Ponto Nodal e nele quem é castrado não é o sujeito, mas sim a mãe. Quando a criança não ultrapassa esse Ponto Nodal, ela mantém certa forma de identificação com o objeto da mãe. Para essa identificação existem graus, e é precisamente ela que leva o sujeito à neurose, psicose ou perversão. O sujeito psicótico é então aquele onde o Nome-do-Pai é foracluído e permanece identificado ao objeto da mãe.

\section{O Paradigma Joyce}

Em seu chamado último ensino, Lacan introduz à teoria dos nós, em seus Seminários 22 (Lacan, n.d.) e 23 (Lacan, 2005c). No início do Seminário 23: O Sinthoma, Lacan explica que retomou a antiga grafia da palavra symptôme sintoma, e diz que isto marca uma data, da injeição no grego do que ele chama de lalíngua. Relata que utilizou o brasão dos Borromeu para estabelecer a condição de sua teoria dos nós, a de que, a partir de três anéis, se fizesse uma cadeia tal que o rompimento de apenas um, o do meio, tornasse os outros dois livres um do outro. Estabelece então que o pai é um sinthoma que cria o laço enigmático do imaginário, do simbólico e do real. Designa também que o Complexo de Édipo é, enquanto tal, um sintoma. "É na medida em que o Nome-do-Pai é também Pai do Nome, que tudo se sustenta, o que não torna o sintoma menos necessário" (Lacan, 2005c, p.23).

Segundo o autor, o nó borromeano consiste na relação que faz com que tudo que é envolvido em um de seus círculos acabe envolvendo o outro. Sobre o caráter fundamental da utilização do nó borromeano, Lacan destaca:

O caráter fundamental dessa utilização do nó é ilustrar a triplicidade que resulta de uma consistência que só é afetada pelo imaginário, de um furo como fundamental proveniente do simbólico, e de uma ex-sistência que, por sua vez, pertence ao real e é inclusive sua característica fundamental. (Lacan, 2005c, p.36)

Segundo o autor, o corpo do sujeito, do falasser só tem estatuto respeitável, graças ao nó. É estudando o caso de James Joyce que Lacan ilustra sua teoria do nó borromeano e aborda seu quarto termo, o sinthoma, uma vez que no caso do escritor ele completa o nó do imaginário, do simbólico e do real. Assim estabelece que quando se passa do nó de três para o de quatro, em que o sinthoma é introduzido, o nó de três enquanto tal desaparece, não há mais um nó, ele fica sustentado apenas pelo sinthoma. O mínimo em uma cadeia borromeana é, então, sempre constituído por um nó de quatro.

Podemos salientar então, que há uma dinâmica dos nós. O nó de trevo, deduzido do nó borromeano não é um nó, mas uma cadeia.

Ele tem o sentido que permite situar o sentido em algum lugar da cadeia borromeana. [...] O nó é deduzido do fato de que essas três rodinhas de barbante do imaginário, do real e do simbólico fazem nó. [...] basta que haja um erro nesse nó de três para que ele se reduza à rodinha. (Lacan, 2005c, p.89)

Sempre há um lapso do nó, e o nó de três fracassa sempre, inclusive na neurose. Então no paradigma Joyce o déficit é generalizado. "Com o lapso generalizado do nó cai em evidência que estamos todos em déficit, que todos viemos com o nó mal feito, com lapso do nó" (Dafunchio, 
2008, p.65).

Neste momento do ensino, o que fará diferença entre as estruturas clínicas é de que maneira se soluciona o lapso do nó. É uma clínica diferencial da solução. De acordo com a solução que o sujeito encontra para o lapso do nó é que a estrutura se vislumbra. "Nesta clínica da solução, o que se inverte a respeito do paradigma Schreber é que a mesma não é a neurose, mas a psicose. A estrutura é pensada a partir da psicose, por isso Lacan pensa o nó a partir do caso Joyce" (Dafunchio, 2008, p.65).

Considerar os três registros e seus enodamentos permite pensar nas psicoses não desencadeadas, nos desencadeamentos e nas soluções. Passa-se de 'A psicose', do paradigma Schreber, para a pluralização de 'as psicoses', com a possibilidade de pensar diferentes enodamentos de acordo com o tipo de psicose.

Schejtman (2000) discorre sobre uma questão fundamental, a diferença entre neurose e psicose no ensino do Seminário 23, na qual as psicoses implicam reparações do lapso do nó que não são borromeanas. Na neurose, o lapso estrutural do nó faz com que os três se soltem e são reestabelecidos por um quarto, o sinthoma ou Nome-do-Pai, que os enodam borromeanamente. Ao passo que na psicose isso não ocorre, o enodamento possível não faz com que ao cortar um aro se soltem os demais.

Acompanhamos com Dafunchio (2008), uma teoria sobre os nós de diferentes tipos de psicose. Na esquizofrenia, o lapso faz com que se solte o imaginário. O simbólico e o real continuam amarrados, o que localizamos como uma interpenetração entre o simbólico e o real. Isto explicaria as alucinações verbais e todos os fenômenos elementares das psicoses, como o desenlace do imaginário daria conta do desastre imaginário.

Podemos deduzir, a partir do Seminário 23, que Lacan diagnostica Joyce como um esquizofrênico não desencadeado. No caso do escritor o desenlace do imaginário não se produz porque ele o evita por meio de uma suplência, de um sinthoma que reparará o lapso do nó. O sinthoma é o que repara a cadeia, no caso dela não mais existir, ou seja, se em dois pontos forem cometidos o que Lacan chamou de erro. O lapso pode ser corrigido no ponto exato onde ele se produz ou nos outros dois pontos que têm como consequência. A solução de Joyce para o lapso é uma reparação sinthomática do mesmo. O que Lacan vai nos mostrar é que Joyce se faz um Nome Próprio às custas do Nome-do-Pai, se faz um Nome Próprio através de sua escrita, de seu desejo de ser famoso e de ser estudado pelos universitários.

Desde o paradigma Joyce, não se trata de apontar apenas a construção da metáfora delirante como solução para a psicose e assim novos caminhos se desvelam. Com a perspectiva dos nós abrem-se novos recursos e outras muitas soluções possíveis. É nesta perspectiva que iremos também considerar a droga, como um recurso possível encontrado pelo sujeito para fazer suplência em sua psicose.

\section{Desencadeamento e Suplência}

A partir do paradigma Joyce, vimos com Lacan (2005c) uma outra perspectiva da psicose, abordada sob o viés do sinthoma. Podemos pensar, a partir deste paradigma, em múltiplas soluções encontradas pelo sujeito para lidar com sua psicose. Sendo assim, a teoria lacaniana dos nós nos permite abordar a singularidade das soluções inventadas pelos sujeitos através da amarração única que cada um faz dos três registros.

O termo "desencadeamento" aparece inicialmente na tese de doutoramento de Lacan (1987), quando o autor se dedica ao caso Aimèe abordando a passagem ao ato e a maternidade diretamente ligadas à estabilização e ao desencadeamento de sua psicose. Este termo ganha força conceitual em sua obra quando Lacan (1997) se dedica ao estudo das psicoses em seu Seminário 3 e em seu escrito De uma questão preliminar (Lacan, 1998a). Nesses textos, discorre sobre a conjuntura dramática envolvida na cena do desencadeamento das psicoses, exemplificada por ele como diversas situações que podem ocorrer na vida de um sujeito, como o nascimento de um filho, a perda de um ente querido ou até uma promoção profissional. Faz-se importante salientar aqui que qualquer tentativa de se obter um sentido ou uma lógica nesses acontecimentos é arriscada (Maleval, 1992).

Por falta da referência simbólica do Nome-do-Pai, o sujeito psicótico funciona no registro imaginário, onde a relação especular é a regra. Segundo Quinet (2006), o psicótico encontra-se muitas vezes, antes de um primeiro surto, numa relação dual com o duplo imaginário, e o pai, sem função simbólica, é apreendido apenas como uma imagem.

O registro imaginário que dá forma à realidade do sujeito psicótico apresenta três tempos, o primeiro chamado de Prépsicose, onde o sujeito se vale das bengalas imaginárias; o segundo tempo do desencadeamento, onde há a queda dessa identificação e como consequência a dissolução imaginária; e um terceiro tempo, o da estabilização, da restauração do imaginário, que será explanado adiante neste trabalho.

O desencadeamento da psicose é, de acordo com Lacan (1998a), efeito do encontro do sujeito com Um-pai. Um sujeito estruturalmente foracluído do Nome-do-Pai e Umpai, que pode ser uma pessoa ou situação que de uma outra cena se interpõe e se impõe ao sujeito, "interpelando-o no cerne de suas relações com o outro, exigindo-lhe uma 
resposta no plano significante, aí mesmo onde ele se encontra sem prumo." (Souza, 1991, p.38). Ainda sobre a desestabilização com referência à falta do Nome-do-Pai, Lacan nos diz: “(...) pelo furo que abre no significado, dá início à cascata de remanejamentos do significante de onde provém o desastre crescente do imaginário" (Lacan, 1998a, p.584).

A cena do desencadeamento é composta, segundo Lacan (1998a), de algumas condições. A primeira condição a que ele se refere é aquela de ordem estrutural, a saber, a foraclusão do Nome-do-Pai no lugar do Outro.

É num acidente desse registro [da linguagem] e do que nele se realiza, a saber, na foraclusão do Nome-do-Pai no lugar do Outro, e no fracasso da metáfora paterna, que apontamos a falha que confere à psicose sua condição essencial, com a estrutura que a separa da neurose. (Lacan, 1998a, p.582)

A segunda condição a que Lacan se refere concerne ao abalo das identificações que sustentam o sujeito em sua vivência anterior ao desencadeamento. É por meio dessas identificações que o sujeito elabora as compensações imaginárias, as chamadas "bengalas". A terceira condição refere-se, no caso do desencadeamento clássico, a uma situação específica que invoca no sujeito o Nome-do-Pai, que lhe é faltante e como já dito anteriormente, “(...) dá início a uma cascata de remanejamentos do significante, de onde provém o desastre crescente do imaginário." (Lacan, 1998a, p. 584).

O conceito de desencadeamento que nos importa neste trabalho é aquele do último ensino. Se a cadeia borromeana é um nó feito de buracos, os elos são vazios e contornados por uma borda. O registro Imaginário é aquele que, articulado com os registros Real e Simbólico, forma o nó responsável pela organização do mundo exterior e do mundo interno do sujeito e segundo Souza (1991) sem o qual a realidade psíquica não poderia se constituir. O Nome-do-Pai é aquele que permite que os três registros - Simbólico, Imaginário e Real - permaneçam atados.

Assim, Lacan localiza o desencadeamento como algo que desata o nó. Se o nó é composto pelos registros Real, Simbólico e Imaginário, amarrados e sustentados por algo, no caso da psicose esse "algo", antes do desencadeamento, são as bengalas imaginárias que na ocasião do mesmo não bastam na chamada ao Nome-do-Pai e deixam os registros soltos, à mercê do Imaginário.

Se os registros RSI precisam de algo que os amarre e não fazem essa amarração por si mesmos, é necessário que algo a faça. É preciso uma ação suplementar, que, no caso da psicose, não é feita pelo Nome-do-Pai, como na neurose, mas sim por algum outro significante que sustenta o sujeito antes do desencadeamento. A ruptura do significante que faz essa amarração é uma resposta do sujeito frente ao gozo fálico.

Soler (2007) diz que a psicose apresenta constantemente casos de desencadeamentos repentinos, inesperados, e os chama de desencadeamentos-surpresa. A autora afirma que para se pensar ao nível da causação da psicose é preciso não levar em conta só o Nome-do-Pai foracluído, pois a foraclusão por si só não é causa suficiente da psicose. Segundo a autora "é preciso uma causa adjunta para que se desencadeie a psicose, é preciso uma causa complementar, a qual é ocasional" (Soler, 2007, p.200). É essa causa ocasional que produz um apelo ao Nome-do-Pai e torna sua falta eficiente, e esse apelo se produz pelo encontro de Um pai real. Um com letra maiúscula, como escreve o próprio Lacan.

Para aludir à suplência psicótica, precisamos primeiramente nos debruçar sobre o termo estabilização. Para Colette Soler, estabilização não é um termo do vocabulário psicanalítico, mas sim “(...) uma palavra que constitui uma imagem e que, convém dizer, presta-se a todas as confusões e também a todas as imprecisões" (Soler, 2007, p.193). Segundo a autora, a psiquiatria se utiliza do termo estabilização por não ousar dizer de uma "cura" para a psicose ou até mesmo dizer de "efeito terapêutico" como fazem em relação à neurose.

Para adotarmos a noção de estabilização é preciso então que façamos a diferenciação do mesmo no vocabulário psiquiátrico e no psicanalítico. "Decerto é preciso distinguir uma estabilização, no sentido estrito do termo, de uma organização dos distúrbios da psicose" (Soler, 2007, pp.207208). É do vocabulário lacaniano que se extraem os termos de metáfora e suplência, a partir dos quais tentamos dar um sentido ao termo estabilização.

O termo metáfora aparece em relação à psicose primeiramente no Seminário 3, em relação à ambigüidade do significante e do significado. Lacan distingue então a metáfora paterna: o Nome-do-Pai que substitui o Desejo da Mãe faz surgir no lugar do significado a significação do falo. Tem como efeito separar o sujeito da vacilação inerente à relação especular com a mãe. No texto "A instância da letra no inconsciente", redigido por Lacan em maio de 1957, pouco antes da Questão preliminar, Lacan conclui que o sintoma é uma metáfora, partindo assim para a definição diferencial da psicose: os fenômenos psicóticos têm uma estrutura de linguagem, mas o sintoma psicótico não é uma metáfora, mas sim a ausência dela. "A metáfora é um princípio de estabilização. Ela cria um ponto de parada no deslizamento do significado sob o significante" (Soler, 2007, p.196). Ou seja, a Metáfora Paterna estabiliza no sujeito o significante e o significado. Estabelecendo uma 
ligação entre metáfora e estabilização, a autora nos coloca então a tese de que uma metáfora3 pode substituir outra como princípio de estabilização.

O que interessa é a problemática do ponto de basta em seus efeitos estabilizadores. A questão é saber como é possível restaurar aquilo que é desatrelado na perseguição e no desastre do imaginário pelo deslocamento das identificações, de tal sorte que o gozo entre na dialética do discurso. Fazer o gozo entrar nos limites do discurso e do vínculo social, essa é a questão, com efeito. (Soler, 2007, p. 203)

De todas as consequências que o Nome-do-Pai foracluído determina e que constituem a estruturação da experiência psicótica, advém um trabalho de reconstrução. Este trabalho vem para criar um novo mundo de significações para o sujeito psicótico, sistematizando o delírio, a metáfora delirante, ou, como destaca Souza (1991), a teia de palavras e imagens, substituindo o Nome-do-Pai, ou mais do que isso, sendo um dos Nomes-do-Pai.

Segundo Soler (2007), as soluções mais identificáveis da psicose "são as que se servem de um simbólico de suplência, que consiste em construir uma ficção diferente da ficção edipiana e em levá-la a um ponto de estabilização, obtida pela metáfora delirante" (Soler, 2007, p.187). Essa metáfora é bem exemplificada no caso de Schreber.

Isso significa que existe uma clínica dos substitutos do Nome-do-Pai que exercem a função do que Lacan (2005c) chamou em seu último ensino de reparação sinthomática.

A metáfora paterna é então, um conceito utilizado por Lacan na década de 50, para identificar a metáfora delirante como tentativa de solução para o sujeito psicótico, ou seja, como um meio de estabilização da psicose. Ao passarmos para o conceito de suplência, será necessário localizá-lo no ensino lacaniano da década de 70, onde o termo é utilizado.

A possibilidade de outros significantes ocuparem a função de Nome-do-Pai levou Lacan (2005b) em seu seminário Nomes do pai, a postular sua pluralização, os Nomes-do-Pai, conceituação relativa à idéia de suplência. No Seminário 23, Lacan (2005c) inaugura uma quarta instância responsável por enodar os registros RSI de modo borromeano, fazendo uma suplência, instância à qual dá o nome de Sinthoma.

O Sinthoma não é sintoma-metáfora, não é sintomaletra e não se confunde com os três registros, Real, Imaginário e Simbólico. Ele é uma quarta consistência, que enoda os três registros.

No enodamento pelo Sinthoma, os registros Real, Simbólico e Imaginário se encontram enlaçados de modo borromeano e o Sinthoma é aquele que faz a amarração dos

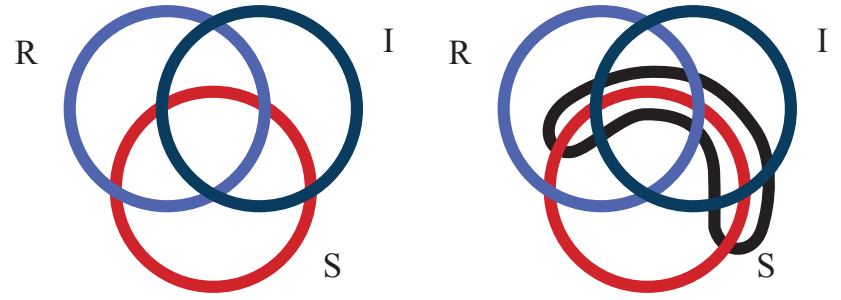

Figura 5. Três anéis RSI separados e depois o nó borromeano de quatro aros com reforço (Sinthoma) (Lacan, 2005c, p. 21).

mesmos. Nesta cadeia de quatro registros não há nenhuma interpenetração. "Aqui este Sinthoma com 'formato de orelha' repara de modo borromeano e simultâneo, os dois lapsos produzidos, impedindo que os três registros possam ir cada um para seu lado." (Schejtman, 2008, p.43, tradução nossa). Essa amarração feita pelo Sinthoma é chamada por Lacan de reparação sinthomática. Um exemplo de reparação sinthomática é mostrado por Lacan (2005c) no caso de James Joyce, onde o escritor encontra no ego o seu Sinthoma, uma suplência para a falha de seu enodamento.

$\mathrm{O}$ nó borromeano clássico corresponde na realidade a um sujeito ideal, e este não existe. No que concerne às três estruturas possíveis de lapsos de enodamento, neurose, psicose e perversão, o Sinthoma é aquele que repara esses lapsos. No lapso será feito um Sinthoma que o amarre para que os registros não fiquem soltos e ocorra a reparação - ou suplência.

O sujeito na psicose é então obrigado a fazer uma suplência do Nome-do-Pai para se manter na realidade. Essa suplência é o trabalho da psicose, que será sempre uma maneira de o sujeito tratar os retornos no real do que é foracluído do simbólico, de efetuar conversões que civilizem o gozo até torná-lo suportável.

O delírio é uma auto-elaboração, na qual se manifesta de maneira evidente o que Lacan (1998a) chama de "eficácia do sujeito", mas não constitui, evidentemente, sua única expressão:

O delírio é claro, não constitui a única manifestação: o fato de falarmos de pré-psicose, antes do desencadeamento, e de eventuais estabilizações, depois dele, indica bem que a foraclusão é passível de ser compensada em seus efeitos, sob formas que não se reduzem unicamente à elaboração delirante. (Soler, 2007, p. 185)

Soler (2007) aponta ainda que podem existir diversos tipos de solução para a psicose. A solução que consiste em cobrir a coisa com uma ficção apensa a um significante ideal funciona em muitos casos, mas não exige forçosamente a inventividade delirante do sujeito. Um tipo de solução pode ser aquela que permite ao sujeito novamente deslizar sobre 
o significante que fazia seu mundo sustentar-se, e pode vir de um encontro que vem corrigir o da perda desencadeadora. De acordo com a autora, nesta solução o sujeito não inventa, mas toma emprestado do Outro um significante que lhe permite, pelo menos por algum tempo, cobrir com um ser de pura conformidade o ser imundo que ele tem a certeza de ser.

A solução que a autora coloca como civilizadora da coisa pelo simbólico é também via de sublimações criacionistas, e a mesma cita como exemplo sublimações convocadas na psicose por nomes conhecidos como Joyce, Rousseau e Van Gogh, e diz que elas têm uma função análoga a que é o delírio para Schreber.

Existem ainda outros tipos de solução que não usam o simbólico, mas procedem de uma operação real sobre o real do gozo não aprisionado na rede da linguagem. Assim pode ser considerada a obra, onde se deposita um gozo que é transformado até se tornar estético, enquanto o objeto produzido impõe-se ao real.

\section{Referências}

Dafunchio, N. S. (2008). Confines de las psicosis. Buenos Aires: Del Bucle.

Lacan, J. (1987). Da psicose paranóica em suas relações com a personalidade. Rio de Janeiro: ForenseUniversitária.

Lacan, J. (1997). O seminário, Livro 3: As Psicoses (19551956). Rio de Janeiro: Jorge Zahar.

Lacan, J. (1998a). De uma questão preliminar para todo tratamento possível da psicose. In J. Lacan, Escritos (pp.537-590). Rio de Janeiro: Zahar.

Lacan, J. (1998b). A instância da letra no inconsciente ou a razão em Freud. In J. Lacan, Escritos (pp.496-536). Rio de Janeiro: Zahar.

Lacan, J. (1999). O Seminário, Livro 5: as formações do inconsciente (1957-58). Rio de Janeiro: Zahar.

Lacan, J. (2005a). O seminário, Livro 10: A angústia (19621963). Rio de Janeiro: Zahar.

Lacan, J. (2005b). Nomes do Pai. Rio de Janeiro: Jorge Zahar Editor.

Lacan, J. (2005c). O Seminário, Livro 23: O sinthoma (1975-1976). Rio de Janeiro: Zahar.

Lacan, J. (n.d.) O seminário, Livro 22: R.S.I. Ed. Eletrônica Folio Views.

Maleval, J-C. (1992). La forclusión del Nombre del Padre: El concepto y su clínica. Buenos Aires: Paidós.
Miller, J-A. (2002). Últimas lições. Cours de Orientation lacanienne III, 4 [Inédito].

Miller, J-A. (2002) Le dernier enseignement de Lacan. Revue de La Cause Freudienne, Revue de Psychanalyse 51(5), 7-34.

Motta, M. B. (2003). A psicanálise na globalização. Latusa Digital (1), 1-8. Recuperado de http://www.latusa.com. br/latusa_revista_digital_1.html

Quinet, A. (2006). Teoria e clínica da psicose ( $3^{\mathrm{a}}$ ed.). Rio de Janeiro: Forense Universitária.

Schejtman, F. (2000) Acerca de los nudos. In F. Schejtman, Las dos clinicas de Lacan. Buenos Aires: Ed. Tres Haches.

Schejtman, F. (2008). Síntoma y Sinthome. Ancla 2 Encadenamientos y desencadenamientos. Revista de la Cátedra II de Psicopatología, Facultad de Psicología, Universidad de Buenos Aires (1), 15-59.

Soler, C. (2007). O inconsciente a céu aberto da psicose. Rio de Janeiro: Jorge Zahar.

Souza, N. S. (1991). A Psicose: Um Estudo Lacaniano. Rio de Janeiro: Campus.

\section{Endereço para correspondência:}

Flávia Costa Tótoli

Endereço: Rua: Mestre João Silvério, 684, apto 302.

Bairro: Jardim Arizona. Sete Lagoas/MG - 35700-381.

E-mail: flavia.totoli@gmail.com

\section{Endereço para correspondência:}

\section{Cristina Moreira Marcos}

Endereço: Rua Paschoal Carlos Magno, 68. Bairro: Ouro

Preto. Belo Horizonte/MG - 31310-510.

E-mail: cristinammarcos@gmail.com 